\title{
BMJ Open Bronchial Thermoplasty Global Registry (BTGR): 2-year results
}

\author{
Alfons Torrego (10 , ${ }^{1}$ Felix J Herth, ${ }^{2}$ Ana M Munoz-Fernandez, ${ }^{3}$ Luis Puente, ${ }^{4}$ \\ Nicola Facciolongo, ${ }^{5}$ Stephen Bicknell, ${ }^{6}$ Mauro Novali, ${ }^{7}$ Stefano Gasparini, ${ }^{8}$ \\ Martina Bonifazi, ${ }^{8}$ Keertan Dheda, ${ }^{9}$ Felipe Andreo, ${ }^{10}$ Praha Votruba, ${ }^{11}$ \\ David Langton, ${ }^{12}$ Javier Flandes, ${ }^{13}$ David Fielding, ${ }^{14}$ Peter I Bonta, ${ }^{15}$ \\ Dirk Skowasch, ${ }^{16}$ Christian Schulz, ${ }^{17}$ Kaid Darwiche, ${ }^{18}$ Edmund McMullen, ${ }^{19}$ \\ G. Mark Grubb, ${ }^{19}$ Robert Niven ${ }^{20}$
}

To cite: Torrego A, Herth FJ, Munoz-Fernandez AM, et al. Bronchial Thermoplasty Global Registry (BTGR): 2-year results. BMJ Open 2021;11:e053854. doi:10.1136/ bmjopen-2021-053854

- Prepublication history and additional supplemental material for this paper are available online. To view these files, please visit the journal online (http://dx.doi.org/10.1136/ bmjopen-2021-053854).

Received 26 May 2021 Accepted 25 November 2021

Check for updates

(C) Author(s) (or their employer(s)) 2021. Re-use permitted under CC BY-NC. No commercial re-use. See rights and permissions. Published by BMJ.

For numbered affiliations see end of article.

Correspondence to

Dr Alfons Torrego;

atorrego@santpau.cat

\section{ABSTRACT}

Objectives Bronchial thermoplasty (BT) is a device-based treatment for subjects $\geq 18$ years with severe asthma not well controlled with inhaled corticosteroids and long-acting beta-agonists. The Bronchial Thermoplasty Global Registry (BTGR) collected real-world data on subjects undergoing this procedure.

Design The BTGR is an all-comer, prospective, open-label, multicentre study enrolling adult subjects indicated for and treated with BT.

Setting Eighteen centres in Spain, Italy, Germany, the UK, the Netherlands, the Czech Republic, South Africa and Australia

Participants One hundred fifty-seven subjects aged 18 years and older who were scheduled to undergo BT treatment for asthma. Subjects diagnosed with other medical conditions which, in the investigator's opinion, made them inappropriate for BT treatment were excluded. Primary and secondary outcome measures Baseline characteristics collected included demographics, Asthma Quality of Life Questionnaire (AQLQ), Asthma Control Test (ACT), medication usage, forced expiratory volume in one second and forced vital capacity, medical history, comorbidities and 12-month baseline recall data (severe exacerbations (SE) and healthcare utilisation). SE incidence and healthcare utilisation were summarised at 1 and 2 years post-BT.

Results Subjects' baseline characteristics were representative of persons with severe asthma. A comparison of the proportion of subjects experiencing events during the 12 months prior to BT to the 2-year follow-up showed a reduction in SE $(90.3 \%$ vs $56.1 \%$, $p<0.0001)$, emergency room visits $(53.8 \%$ vs $25.5 \%$, $\mathrm{p}<0.0001)$ and hospitalisations $(42.9 \%$ vs $23.5 \%$, $\mathrm{p}=0.0019$ ). Reductions in asthma maintenance medication dosage were also observed. AQLQ and ACT scores improved from 3.26 and 11.18 at baseline to 4.39 and 15.54 at 2 years, respectively $(p<0.0001$ for both AQLQ and ACT).

Conclusions The BTGR demonstrates sustained improvement in clinical outcomes and reduction in asthma medication usage 2 years after BT in a real-world population. This is consistent with results from other BT randomised controlled trials and registries and further supports improvement in asthma control after BT. Trial registration number NCT02104856.
Strengths and limitations of this study

The Bronchial Thermoplasty Global Registry (BTGR):

- Was designed to collect data on subjects undergoing bronchial thermoplasty treatment for asthma in a 'real-world' setting for 2 years at 18 clinical sites to investigate the effect of bronchial thermoplasty on severe asthma exacerbations, emergency department visits and hospitalisations.

- One limitation of this study was that it was registrybased and, thus, was a single-arm study with no comparator rather than a randomised controlled trial.

- Another limitation is that the level of investigator experience with the bronchial thermoplasty procedure varied between clinical sites and some sites were inexperienced with the conduct of clinical studies.

- The BTGR was also limited by a high attrition rate at 2 years post-treatment; approximately one-third of enrolled subjects dropped out of the study.

\section{INTRODUCTION}

Asthma is a chronic condition of the airways characterised by airway inflammation, excess mucus production, airway hyperresponsiveness and airway remodelling. Ten per cent of patients have severe, poorly controlled asthma with frequent symptoms despite optimal therapy with inhaled corticosteroids (ICS) and long-acting bronchodilators (LABA), and this group accounts for more than $80 \%$ of the healthcare costs associated with the disease. ${ }^{1-3}$

Bronchial thermoplasty (BT) is the only U.S. Food and Drug Adminsitration (FDA)approved non-pharmacologic procedure approved for the treatment of asthma. It is indicated for patients 18 years and older with severe persistent asthma who is not well controlled with ICS and LABA. During the $\mathrm{BT}$ procedure, radiofrequency energy is used to heat the airway walls in a controlled manner. The mechanism of action may be, in 
part, a lasting reduction in airway smooth muscle mass after the procedure and downstream mechanical and physiological actions resulting from this reduction. ${ }^{4-10}$ Reduction in airway smooth muscle has been shown to be associated with clinical improvement seen in patients undergoing BT. ${ }^{56}$ Other structural and immunohistological changes, including reduction in reticular basement membrane thickness, reduction in collagen type I deposition and changes in neuroendocrine cells and bronchial nerve endings, may also contribute to clinical improvement. ${ }^{451112}$

Several randomised controlled clinical trials of BT have been carried out in patients with moderate to severe asthma-including the AIR (Asthma Intervention Research), RISA (Research In Severe Asthma) and AIR2 (Asthma Intervention Research 2) studies. ${ }^{13-19}$ All of these randomised controlled trials (RCTs) have concluded that BT is a safe and effective procedure. Subjects enrolled in these studies experienced improvements in asthma control following BT, including decreased numbers of asthma exacerbations, emergency room (ER) visits for asthma and hospitalisations as well as improved quality of life as measured by Asthma Quality of Life Questionnaire (AQLQ) scores. ${ }^{16}$ Clinical improvements persisted to at least 5 years after the last BT treatment. ${ }^{20}{ }^{21}$ Additionally, several recent studies have examined the effectiveness of BT outside the confines of an RCT, including the PAS2 study in the USA and Canada ${ }^{22}$ and a study in Australia in severe asthmatics. ${ }^{23}$ Data from both of these studies suggest that $\mathrm{BT}$ is safe and effective in populations of patients who may have more severe asthma than those included in the previous RCTs.

Nevertheless, additional data outside RCT studies can provide reassurance that these results can be duplicated in clinical practice. The Bronchial Thermoplasty Global Registry (BTGR) was designed to collect outcome data on subjects undergoing BT procedures in a 'real-world' setting. In this manuscript, we describe the clinical outcomes for BTGR subjects over the 2 years following BT treatment.

\section{METHODS}

\section{Study design}

BTGR is a prospective, open-label, single-arm, observational registry (clinicaltrials.gov) designed to collect outcome data as well as clinical and demographic characteristics of patients undergoing $\mathrm{BT}$ treatment in the 'real-world' clinical setting. BTGR-enrolled subjects from 23 January 2014 to 28 December 2016 at 18 centres in Spain, Italy, Germany, the UK, the Netherlands, the Czech Republic, South Africa and Australia, and the last patient completed follow-up and exited the study on 26 June 2019.

\section{Study subjects}

Between 2014 and 2016, BTGR enrolled 157 subjects aged 18 years and older who were scheduled to undergo BT treatment with the Alair System (Boston Scientific Corporation, Marlborough, Massachusetts). Subjects diagnosed with other medical conditions which, in the investigator's opinion, made them inappropriate for BT treatment were excluded. All medications were administered as part of the local standard of care asthma treatment and for BT procedures; there were no additional medication requirements mandated by this registry.

\section{Treatment}

All BTGR subjects were scheduled to undergo three bronchoscopy procedures performed approximately 3 weeks apart. BT treatments were administered using the Alair Bronchial Thermoplasty System (Boston Scientific, Marlborough, Massachusetts) per FDA labelling by the investigators and as previously described. ${ }^{1516}$

\section{Follow-up}

BTGR subjects were instructed to report any adverse events (AEs) occurring as a result of the BT procedure to clinic staff at any time. Subjects were evaluated at 6 weeks following the third BT procedure (the end of the treatment period) and at 6,12, 18 and 24 months after completion of the treatment period. The 6-month and 18-month evaluations were performed either by phone or in the clinic office; the 12-month and 24-month evaluations were performed as office visits.

\section{Outcome measures}

The primary endpoint of the BTGR study was the proportion of subjects who experienced severe asthma exacerbations at 1 and 2 years following BT treatment, which were compared with the proportion of subjects who experienced severe exacerbations during the 12-month period prior to BT. Severe exacerbations were defined in a manner consistent with the National Asthma Education and Prevention Program (NAEPP) Guidelines for the Diagnosis and Management of Asthma as a worsening of asthma symptoms requiring the use of systemic corticosteroids (tablets, suspension or injection). ${ }^{24}$ For patients already taking maintenance systemic corticosteroids, a severe exacerbation was defined as a worsening of asthma symptoms requiring any increase in daily dose of systemic corticosteroids.

Other outcome measures analysed in BTGR included procedural data (including procedure time, anaesthesia type, number of activations of the BT catheter and length of hospital stay), the proportion and rate of emergency room (ER) visits during years 1 and 2 post-BT, the proportion and rate of hospitalisations for asthma during years 1 and 2 post-BT, the proportion and rate of unscheduled office visits during years 1 and 2 post-BT, respiratory AEs occurring during both the treatment period and the posttreatment period, pulmonary function test results $\left(\mathrm{FEV}_{1}\right)$, use of asthma maintenance medications, AQLQ scores, Asthma Control Test (ACT) scores and patient satisfaction survey scores. 


\section{AE monitoring}

A respiratory $\mathrm{AE}$ was defined as any sign, symptom, illness, clinically significant abnormal laboratory value or other adverse medical event associated with the respiratory system that appeared or worsened, regardless of whether it was considered related to the BT procedure. An $\mathrm{AE}$ was considered serious if it required or prolonged hospitalisation, resulted in a permanent impairment of body structure or function, required medical or surgical intervention to prevent such permanent damage or was life threatening or fatal. AEs were collected periprocedurally (defined as the period beginning on the day of the first BT procedure and ending 6 weeks after the last $\mathrm{BT}$ procedure) and at each follow-up visit in the posttreatment period.

\section{Statistical analyses}

Baseline demographics, clinical characteristics and outcomes were summarised with sample size, mean, $\mathrm{SD}$, minimum and maximum for continuous variables and with proportions (numerator over denominator) for binary variables. To compare proportions, counts of events and means between baseline and 2 years, the Fisher's exact test, negative binomial test and t test were used, respectively. For the subgroup analyses, subgroups analysed were those based on gender, age $(<40$ and $\geq 40$ years), baseline body mass index (BMI) $(\leq 30$ and $>30 \mathrm{~kg} /$ $\mathrm{m}^{2}$ ) and smoking history as well as baseline AQLQ $(\leq 4.0$ and $>4.0$ ), baseline oral corticosteroid use, baseline postbronchodilator $\mathrm{FEV}_{1} \%$ predicted $(\leq 70 \%$ and $>70 \%)$ and number of complete catheter activations $(\leq 140$ and $>140) .{ }^{25}$ A generalised linear mixed model with binomial error distribution was fit with factors of the subgroup, time and interaction of subgroup and time with subject as a random effect; if the interaction had a $p$ value $<0.10$, contrasts of time within subgroup and subgroup within time were performed to explore differences. SAS V.9.4 (SAS Institute) was used for all analyses.

\section{Patient and public involvement}

Patients and the public were not involved in the design, conduct, reporting or dissemination of this research.

\section{RESULTS}

\section{Baseline demographics and clinical characteristics of BTGR} subjects

One hundred and fifty-seven adult subjects (mean age $49.8 \pm 12.7$ years) underwent BT; 153 of these subjects had all three BT procedures. These subjects were $65.6 \%$ women with a BMI of $29.2 \pm 6.0 \mathrm{~kg} / \mathrm{m}^{2}$ and had been diagnosed with asthma for $20.7 \pm 14$. 6 years prior to BT treatment. Subjects had a mean AQLQ score of 3.26 \pm 1.10 , a mean ACT score of $11.18 \pm 4.01$ at baseline, and based on the ERS/ATS Guidelines for Severe Asthma, ${ }^{26} 95.5 \%$ of subjects were considered severe asthmatics. These data are summarised in table 1.
Table 1 Baseline information and procedural characteristics of subjects enrolled in the BTGR $(\mathrm{N}=157)$

\begin{tabular}{|c|c|}
\hline Variable & All patients $(\mathrm{N}=157)$ \\
\hline Age (year) & $49.8 \pm 12.7(157)$ \\
\hline \multicolumn{2}{|l|}{ Gender } \\
\hline Female & $65.6 \%(103 / 157)$ \\
\hline Male & $34.4 \%(54 / 157)$ \\
\hline Body mass index $\left(\mathrm{kg} / \mathrm{m}^{2}\right)$ & $29.2 \pm 6.0(156)$ \\
\hline \multicolumn{2}{|l|}{ Medication usage } \\
\hline ICS dose $(\mu \mathrm{g} / \text { day })^{*}$ & $1721 \pm 1239(150)$ \\
\hline LABA dose $(\mu \mathrm{g} /$ day $) \dagger$ & $103.3 \pm 112.5$ (125) \\
\hline SABA used & $69.7 \%(106 / 152)$ \\
\hline $\begin{array}{l}\text { Puffs per day for asthma } \\
\text { symptoms }\end{array}$ & $5.87 \pm 5.59(106)$ \\
\hline OCS (prednisone) used & $47.8 \%(75 / 157)$ \\
\hline Mean dose (mg/day) & $21.0 \pm 19.0(75)$ \\
\hline Omalizumab used & $9.6 \%(15 / 157)$ \\
\hline Years since diagnosis & $20.7 \pm 14.6(155)$ \\
\hline $\begin{array}{l}\text { ERS/ATS guidelines on severe } \\
\text { asthma }\end{array}$ & \\
\hline
\end{tabular}

(ICS $\geq 2000 \mu \mathrm{g} /$ day and LABA/

leukotriene modifiers) or $\geq 2$ severe

$95.5 \%(150 / 157)$

exacerbations in 12 month prior to

first BT or

$\geq 1$ hospitalisation in 12 months prior

to first BT or(post-BD FEV $1<80 \%$ and

$\mathrm{FEV}_{1} / \mathrm{FVC}<0.7$ )

\begin{tabular}{ll}
\hline Patient questionnaires & \\
\hline AQLQ & $3.26 \pm 1.10(148)$ \\
ACT & $11.18 \pm 4.01(61)$ \\
\hline Bronchoscopy information & \\
Number of complete activations & $168.06 \pm 54.09(157)$ \\
Number of incomplete activations & $32.40 \pm 33.40(151)$ \\
Number of total activations & $199.23 \pm 74.98(157)$ \\
\hline
\end{tabular}

*Beclomethasone equivalent.

†Salmeterol equivalent.

ACT, Asthma Control Test; AQLQ, Asthma Quality of Life Questionnaire; BD, bronchodilator; BT, bronchial thermoplasty; BTGR, Bronchial Thermoplasty Global Registry; FEV , forced expiratory volume in one second; FVC, forced vital capacity; ICS, inhaled corticosteroids; LABA, long-acting beta-agonist; OCS, oral corticosteroids; SABA, short-acting beta-agonist.

\section{Severe asthma exacerbations}

During the 12 months prior to BT treatment, 140/155 $(90.3 \%)$ of BTGR subjects had a severe asthma exacerbation, requiring administration of systemic corticosteroids. Two years after BT, only 55/98 (56.1\%) experienced exacerbations $(\mathrm{p}<0.0001$ vs baseline; figure 1 , top panel), which represents a $37.9 \%$ relative reduction in severe exacerbations by year 2 after BT. As shown in figure 1 (top panel), the data for severe exacerbations from BTGR recapitulate 

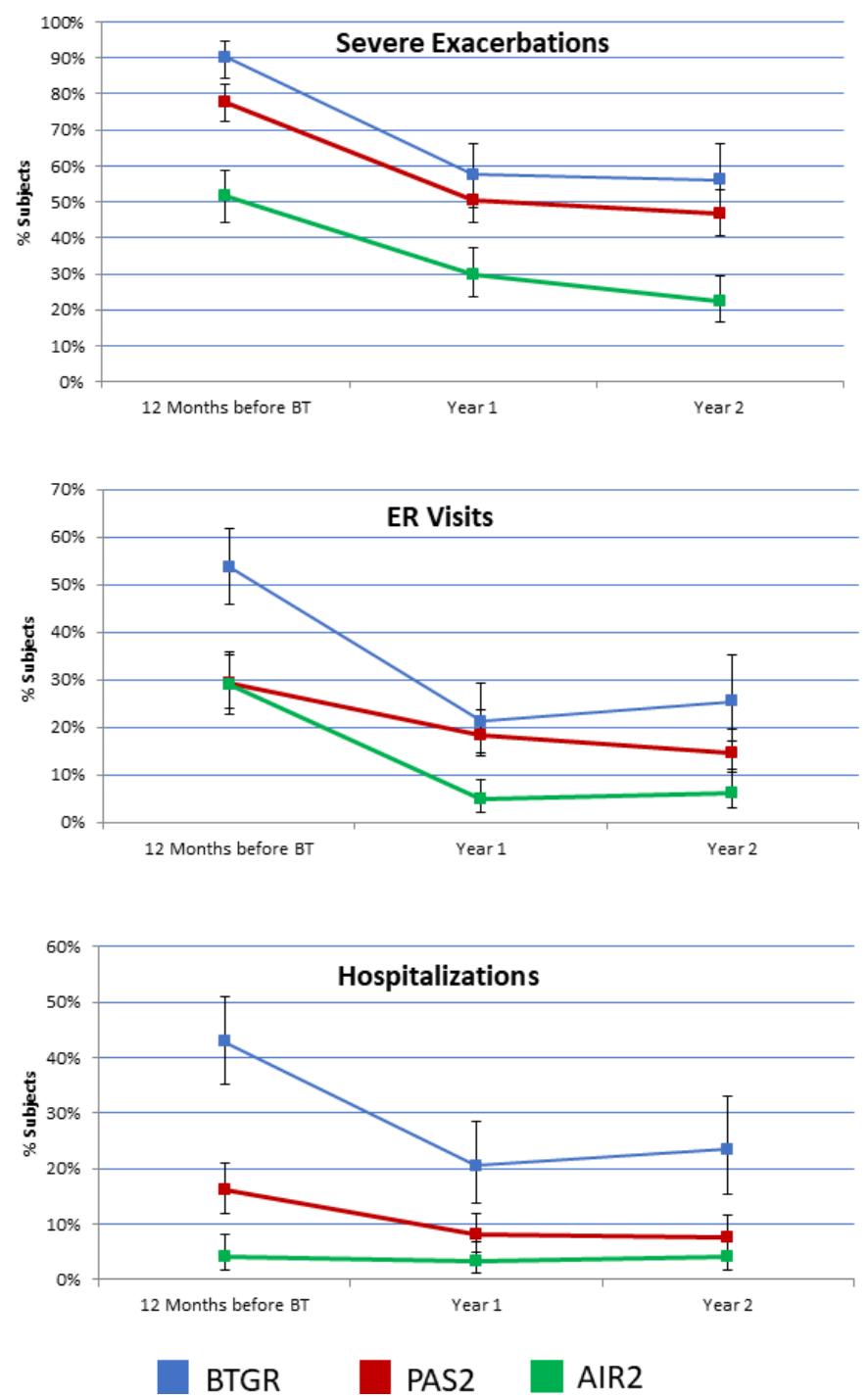

Figure 1 Severe exacerbations (top), emergency room visits (middle) and hospitalisations (bottom) for asthma at baseline and at years 1 and 2 after BT treatment in BTGR subjects. Historical data from the AIR2 (Asthma Intervention Research 2) and PAS2 (Post-FDA Approval Clinical Trial Eveluating Bronchial Thermoplasty in Severe Persistent Asthma) studies are given for comparison. BT, bronchial thermoplasty; BTGR, Bronchial Thermoplasty Global Registry; ER, emergency room.

historical data from previous studies of BT, including the AIR, RISA, AIR2 and PAS2 studies. 141619202227

\section{Healthcare utilisation}

Healthcare utilisation was also reduced after BT treatment (figure 1, middle and bottom panels). In the 12 months prior to BT, $53.8 \%$ of the BTGR subjects visited an ER for asthma symptoms. During year 2 after BT, only 25/98 $(25.5 \%)$ subjects visited the ER for asthma symptoms ( $\mathrm{p}<0.0001$ vs baseline) .

During the 12 months prior to BT treatment, 67/156 $(42.9 \%)$ of BTGR subjects were hospitalised for asthma symptoms. However, during year 2, only 23/98 (23.5\%) were hospitalised $(\mathrm{p}=0.019 \mathrm{vs}$ baseline $)$.
Similar to the data for severe exacerbations, the data for both ER visits and hospitalisations from BTGR also recapitulates historical data for these endpoints from previous studies of BT, including the AIR, RISA, AIR2 and PAS2 studies (figure 1, middle and bottom panels).

Finally, there was a smaller reduction in unscheduled office visits, including those to urgent care facilities, after BT treatment in the BTGR population. During the year prior to BT, 92/156 (59.0\%) of BTGR subjects had unscheduled office visits, but this was reduced to $48 / 98$ $(49.0 \%)$ during year two after BT treatment ( $\mathrm{p}=0.12 \mathrm{vs}$ baseline).

\section{Lung function}

Spirometry was performed at baseline and at each yearly follow-up visit for BTGR subjects (online supplemental table 1). As shown, both $\mathrm{FEV}_{1}$ and forced vital capacity remained stable over the 2-year study period, suggesting that BT did not adversely affect lung function in BTGR subjects.

\section{Maintenance medication usage in BTGR subjects}

Asthma maintenance medication usage at baseline and at 6 months, 1 year and 2 years after BT treatment is shown in table 2 .

As shown, 2years after BT treatment, reductions in several asthma maintenance medications compared with baseline were observed. Mean daily ICS dose had been reduced from $1721 \pm 1239 \mu \mathrm{g} /$ day to $1217 \pm 912 \mu \mathrm{g} /$ day $(\mathrm{p}=0.013)$, and, importantly, the proportion of subjects using maintenance oral corticosteroids (OCS) was significantly reduced from $47.8 \%$ to $24.8 \%$ by 2 years after BT $(\mathrm{p}=0.0002)$. The proportion of subjects using biologics was also reduced from $9.6 \%$ at baseline to $5.7 \%$ at 2 years after BT $(\mathrm{p}=0.045)$.

\section{Quality of life measures and patient satisfaction questionnaires}

Significant improvements were seen in both quality of life measures in BTGR subjects. As shown in figure 2, mean AQLQ scores rose from 3.26 \pm 1.10 at baseline to $4.39 \pm 1.502$ years after BT $(\mathrm{p}<0.0001)$, and at 2 years after BT, 35/56 (62.5\%) of BTGR subjects were classified as AQLQ-based responders to BT (defined as those subjects experiencing an increase in AQLQ score of $\geq 0.5$ from baseline after treatment). Similarly, ACT scores rose from $11.18 \pm 4.01$ at baseline to $15.54 \pm 6.212$ years after BT $(\mathrm{p}<0.0001)$.

When asked at the 24-month visit if they would undergo $\mathrm{BT}$ again and if they would recommend BT to a friend or family member, $87.3 \%$ and $94.9 \%$ of subjects, respectively, replied yes.

\section{Adverse events}

The total number of procedure-related respiratory AEs occurring during the BTGR are summarised in table 3. During the treatment period, $71 / 157$ (45.2\%) subjects experienced procedure-related respiratory AEs related to the BT procedure and $44 / 157(28.0 \%)$ of these were 
Table 2 Asthma maintenance medication usage in BGTR subjects

\begin{tabular}{llllll}
\hline Medication & Baseline & $\begin{array}{l}\text { 6-month } \\
\text { follow-up }\end{array}$ & $\begin{array}{l}\text { 1-year } \\
\text { follow-up }\end{array}$ & $\begin{array}{l}\text { 2-year } \\
\text { follow-up }\end{array}$ & $\begin{array}{l}\text { P value } \\
\text { BL versus 2 years }\end{array}$ \\
\hline ICS dose $(\mu \mathrm{g} /$ day) & $1721 \pm 1239(150)$ & $1564 \pm 1323(72)$ & $1533 \pm 1006(56)$ & $1217 \pm 912(46)$ & 0.013 \\
\hline LABA dose $(\mu \mathrm{g} /$ day) $\dagger$ & $103.3 \pm 112.5(125)$ & $95.4 \pm 97.9(63)$ & $85.6 \pm 75.4(49)$ & $100.5 \pm 180.3(35)$ & 0.91 \\
\hline OCS (prednisone) used & $47.8 \%(75 / 157)$ & $35.4 \%(45 / 127)$ & $23.3 \%(27 / 116)$ & $24.8 \%(26 / 105)$ & 0.0002 \\
\hline Dose (mg/day) & $21.0 \pm 19.0(75)$ & $16.3 \pm 14.2(45)$ & $17.2 \pm 11.9(27)$ & $15.2 \pm 12.8(26)$ & 0.15 \\
\hline Biologic used & $9.6 \%(15 / 157)$ & $3.9 \%(5 / 127)$ & $3.4 \%(4 / 116)$ & $5.7 \%(6 / 105)$ & 0.35 \\
\hline Omalizumab & $9.6 \%(15 / 157)$ & $3.9 \%(5 / 127)$ & $3.4 \%(4 / 116)$ & $2.9 \%(3 / 105)$ & 0.045 \\
\hline Benralizumab & $0.0 \%(0 / 157)$ & $0.0 \%(0 / 127)$ & $0.0 \%(0 / 116)$ & $1.9 \%(2 / 105)$ & 0.16 \\
\hline Mepolizumab & $0.0 \%(0 / 157)$ & $0.0 \%(0 / 127)$ & $0.0 \%(0 / 116)$ & $1.0 \%(1 / 105)$ & 0.40 \\
\hline
\end{tabular}

$P$ values are from the Fisher's exact test for medication usage and a t-test for dosage.

*Beclomethasone equivalent.

†Salmeterol equivalent.

BTGR, Bronchial Thermoplasty Global Registry; ICS, inhaled corticosteroids; LABA, long-acting beta-agonists; OCS, oral corticosteroids.

considered serious. While $61 / 98(62.2 \%)$ and $19 / 98$ (19.4\%) experienced respiratory $\mathrm{AE}$ and serious $\mathrm{AE}$ during year 2 after BT, none of these was related to the $\mathrm{BT}$ procedure. A listing of specific AEs considered related to BT is shown in table 4 , and a listing of unrelated AEs is presented in (online supplemental table 1). Importantly, no deaths were reported during the course of this study.
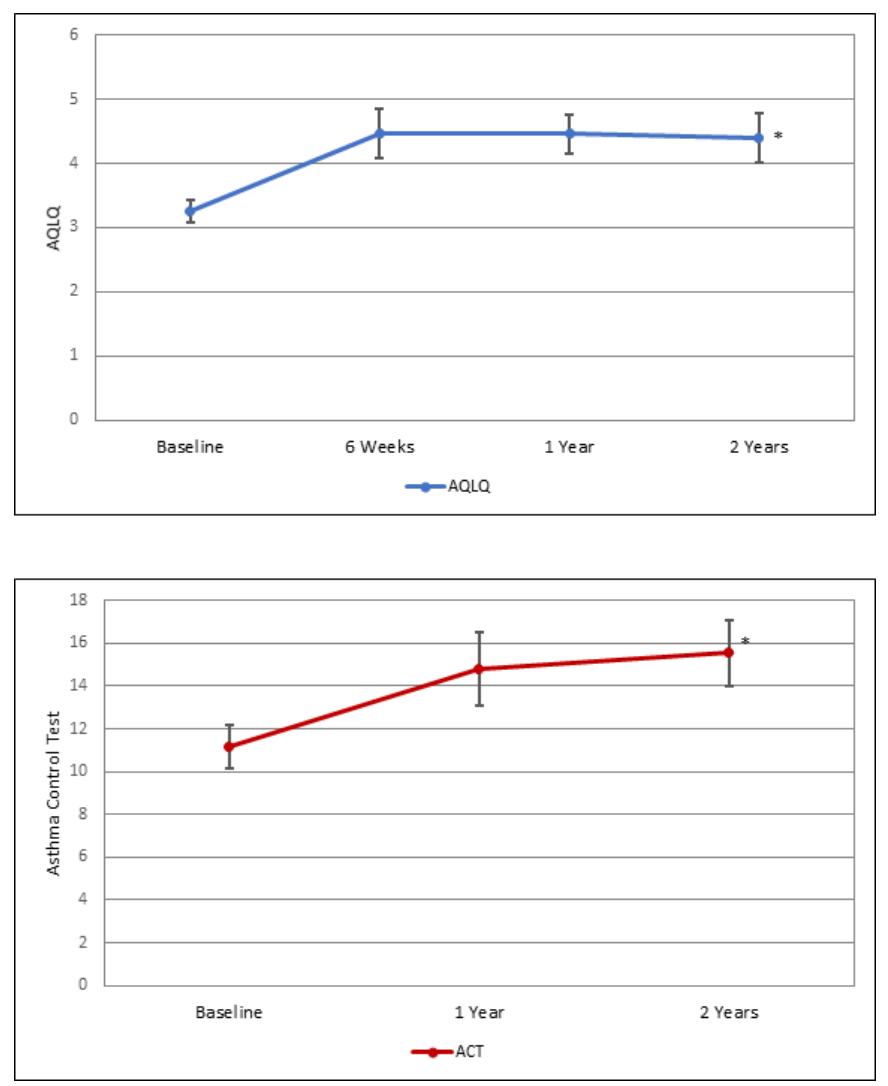

Figure 2 Asthma control test (ACT) values (top panel) and asthma quality of life questionnaire (AQLQ) (bottom panel) at baseline and at years 1 and 2 after bronchial thermoplasty (BT) treatment. *Significantly different than 12 months before BT (baseline).

\section{Responder and subgroup analysis}

Because of the small number of subjects enrolled in the BTGR, we were unable to perform a true responder analysis to identify likely responders to BT. However, we analysed several pairs of mutually exclusive subgroups of BT subjects to see whether BT treatment was effective in reducing the per cent of subjects with severe exacerbations, ER visits and hospitalisations. These subgroup analyses further confirmed that after BT, BTGR subjects experienced significant improvements in all three endpoints; however, we were unable to identify a specific subgroup of subjects for whom BT was most effective (online supplemental figures 1 and 2).

\section{DISCUSSION}

Previous clinical trials of BT (including the AIR, AIR2 and RISA trials) have shown that the procedure is safe and effective, but the subjects enrolled in these clinical trials may not be representative of the most severe asthma cases considered for BT treatment in a 'real-world' clinical practice. A few recent publications have reported on BT in more severe asthmatics who were older and had worse baseline lung function and quality of life. ${ }^{57-9} 232829$ The data indicated a clinical improvement post-BT in these subjects as well as acceptable rates of AEs. The results presented here from the BTGR recapitulate the results from previously published studies and indicate that in the BTGR population, subjects undergoing treatment with BT experienced reductions in severe asthma exacerbations and other healthcare utilisation as well as reductions in asthma maintenance medication usage, particularly OCS. Additionally, clinically meaningful improvements in quality of life, measured by both ACT and AQLQ, were seen out to 2 years after BT treatment in the BTGR population, and these improvements in quality of life measures are similar to those reported in studies of current biologic treatments for asthma. ${ }^{30}$ 
Table 3 Total procedure-related adverse events observed in BGTR subjects

\begin{tabular}{llll}
\hline Adverse events & Treatment period* & 1 year† & 2 years $\neq$ \\
\hline Procedure-related events & & & \\
Respiratory adverse events & $45.2 \%(71 / 157)$ & $2.4 \%(3 / 127)$ & $0.0 \%(0 / 98)$ \\
Respiratory serious adverse events & $28.0 \%(44 / 157)$ & $0.8 \%(1 / 127)$ & $0.0 \%(0 / 98)$ \\
\hline
\end{tabular}

*Events between the date of the first BT procedure and 42 days after the last BT procedure.

†Events between 43 and $365+42$ days after last BT procedure. Patients count in the denominator if they had any one of the events between 43 days and $365+42$ days after the last BT procedure or had $\geq 335+42$ days follow-up after the last BT procedure.

\#Events between $365+43$ and $730+42$ days after last BT procedure. Patients count in the denominator if they had any one of the events between $365+43$ days and $730+42$ days after the last BT procedure or had $\geq 700+42$ days follow-up after the last BT procedure. BT, bronchial thermoplasty; BTGR, Bronchial Thermoplasty Global Registry.

The data from the BTGR add to the already-published body of evidence demonstrating the safety and durable effectiveness of BT in a study population that is more representative of those seen in clinical practice outside the setting of RCTs, in which more restrictive inclusion and exclusion criteria may not allow treatment of the most severe asthmatics. BTGR was an all-comers registry study, and, therefore, there were few inclusion and exclusion criteria for enrolment when compared with many previous studies of BT, including the AIR, RISA, AIR2 and PAS2 studies. The more restrictive eligibility criteria employed in these previous studies ensured that many potential subjects with very severe asthma who would normally be seen in the course of 'real-world' clinical practice were not included in those clinical trials of BT; however, these very ill subjects were not excluded from BTGR. Despite the enrolment of subjects with more severe asthma in BTGR, improvements in asthma control as indicated by reductions in severe exacerbations, ER visits and hospitalisations during BTGR, which were comparable to those observed in the previous studies (figure 1). This suggests that BT is still effective and safe for patients with very severe asthma.

However, this study had several important limitations that warrant discussion. Despite the lack of data defining patient populations that respond best to BT, several recent guidelines have recommended BT treatment for specific subsets of asthmatics. Most recently, an expert consensus panel that examined the fundamental guiding principles for severe asthma treatment-identified BT as the preferred treatment option for severe asthmatics suffering from non-allergic, non-eosinophilic (non-TH2) asthma with variable airflow obstruction as demonstrated by bronchodilator reversibility, who experience persistent symptoms despite treatment with triple therapy. These guidelines also state that $\mathrm{BT}$ should be considered an alternative treatment option for patients with severe eosinophilic or allergic asthma, particularly in patients who do not respond to treatment with anti-IgE and/or anti-IL5 therapies. ${ }^{31} \mathrm{~A}$ recent study by Langton $e t$ al indicated that, in fact, BT treatment was as effective as mepolizumab treatment in this patient population. ${ }^{32}$ However,

\begin{tabular}{lcccc}
\hline Table 4 & Reported asthma-related or bronchial thermoplasty-related adverse events in BTGR subjects & \\
\hline Event & All (N) & Treatment period (N) & 1 year (N) & 2 years (N) \\
\hline Asthma (wheezing/bronchospasm) & 293 & 100 & 115 & 71 \\
Lower respiratory infection (bronchitis, pneumonia) & 82 & 28 & 35 & 17 \\
Upper respiratory tract infection (influenza, viral, sinusitis) & 53 & 16 & 26 & 7 \\
Dyspnoea/breathlessness & 21 & 13 & 2 & 3 \\
Haemoptysis & 13 & 12 & 1 & 0 \\
Cough & 13 & 5 & 6 & 1 \\
Mucous production/plugging & 13 & 10 & 3 & 0 \\
Atelectasis & 11 & 11 & 0 & 0 \\
Laryngitis, laryngospasm, candidiasis & 11 & 7 & 1 & 3 \\
Chest pain/discomfort & 8 & 6 & 0 & 2 \\
Respiratory distress/respiratory failure & 5 & 2 & 3 & 0 \\
Pneumothorax & 2 & 2 & 0 & 0 \\
\hline
\end{tabular}

*In addition, one patient was reported as having bronchomalacia in the treatment period. This was presumed to be a new bronchoscopic finding rather than a sequela of treatment.

BTGR, Bronchial Thermoplasty Global Registry. 
additional data on asthma phenotypes that respond best to BT are required, and, unfortunately, baseline data on asthma phenotype were not routinely collected as a part of the BTGR. Thus, we are unable to address the critical question of whether BT is particularly effective for specific phenotypes in this study population. Another limitation of this registry was that the clinical study sites had varying degrees of experience with the conduct of clinical studies, and this may have contributed to the high patient attrition rate seen in this study. Additionally, not all baseline measurements were required to be collected, and some sites did not routinely collect this information, leading to variability in the number of subjects that could be analysed based on these measures. Finally, the manufacturer of the Alair BT system (Boston Scientific Corporation) sponsored this study, and one of the authors of this manuscript is a full-time employee of the study sponsor.

In conclusion, the data from the BTGR demonstrate sustained improvement in clinical outcomes and reduction in asthma medication usage 2 years after BT in a real-world population. This is consistent with the results from other BT RCTs and registries and further supports improvement in asthma control after BT, suggesting that BT is an effective and safe therapeutic option for severe asthmatics. Future randomised controlled studies designed to further investigate the responses to BT in participants with specific asthma phenotypes and/or studies designed to identify specific responders to BT would be beneficial. Additional clinical studies designed to investigate whether BT treatment can reduce the use of OCS in asthmatics and/or compare responses to BT to those seen with the newer biologic medications are also warranted.

\section{Author affiliations}

${ }^{1}$ Respiratory Department, Hospital de la Santa Creu i Sant Pau, Barcelona, Spain

${ }^{2}$ Thoraxklinik, University of Heidelberg, Heidelberg, Baden-Württemberg, Germany

${ }^{3}$ Respiratory Department, Hospital Josep Trueta, Girona, Catalunya, Spain

${ }^{4}$ Respiratory Department, Hospital General Universitario Gregorio Marañon-Facultad de Medicina Universidad Complutense, Madrid, Spain

${ }^{5}$ AUSL-IRCCS Reggio Emilia Pulmonology Unit, IRCCS Reggio Emilia Pulmonology Unit, Santa Maria Nuova, Italy

${ }^{6}$ Respiratory Department, Gartnavel General Hospital, Glasgow, UK

${ }^{7}$ Respiratory Department, Azienda 0spedaliera Spedali Civili di Brescia, Brescia,

Lombardia, Italy

${ }^{8}$ Respiratory Department, Università Politecnica delle Marche, Ancona, Marche, Italy

${ }^{9}$ Respiratory Department, University of Cape Town, Cape Town, South Africa

${ }^{10}$ Pulmonology Department, Hospital Universitari Germans Trias i Pujol—CIBERES,

Badalona, Barcelona, Spain

${ }^{11}$ Respiratory Department, Klinika Tuberkulozy a Respiracnich Onemocneni, Prague, Czech Republic

${ }^{12}$ Respiratory Department, Frankston Hospital Peninsula Health, Frankston, Victoria, Australia

${ }^{13}$ Respiratory Department, Hospital Universitario Fundacion Jimenez DiazCIBERES IIS-FJD, Madrid, Spain

${ }^{14}$ Respiratory Department, Royal Brisbane and Women's Hospital—Brisbane/AUS, Brisbane, Queensland, Australia

${ }^{15}$ Department of Respiratory Medicine, Amsterdam University Medical Centers, Amsterdam, The Netherlands

${ }^{16}$ Department of Cardiology and Pneumology, University of Bonn, Medizinische Klinik II, Bonn, Germany

${ }^{17}$ Respiratory Department, University Hospital Regensburg, Regensburg, Bayern, Germany
${ }^{18}$ Respiratory Department, Ruhrlandklinik—West German Lung Center, University Medicine Essen, Essen, Germany

${ }^{19}$ Boston Scientific Corp, Marlborough, Massachusetts, USA

${ }^{20}$ Respiratory Department, Central Manchester University Hospitals NHS Foundation Trust, Manchester, UK

Acknowledgements The authors wish to thank Carlos Martinez-Rivera (Hospital Universitari Germans Trias i Pujol, CIBERES, Badalona, Barcelona/ES) for significant contributions to data collection during the conduct of this study. The authors also wish to thank the following employees of Boston Scientific, the sponsor of this study: Frances Nolan, RN for contributions to clinical trial management and Jennifer L. Olson, PhD for editorial assistance with this manuscript.

Contributors Study design, study coordination and manuscript first and final draft: AT, FJFH and RN. Overal responsible of the content and guarantor: AT. Patients' recruitment and follow-up: AT, FJFH, RN, AM-F, LP, NF, SB, MN, SG, MB, KD, FAG, PV DL, JFA, DF, PIB, DS, CS and KD. Trial manager: GMG. Data analysis: EMcM. Final version of the manuscript: AT, FJFH, RN, AM-F, LP, NF, SB, MN, SG, MB, KD, FAG, PV, $\mathrm{DL}, \mathrm{JFA}$, DF, PIB, DS, CS, GMG, EMcM and KD.

Funding This study was sponsored by Boston Scientific Corporation, Marlborough, MA, USA.

Competing interests $\mathrm{FH}$ received personal fees for ad board activities and lecture fees from Pulmonx, BTG, Olympus, and Uptake. AMF reports the receipt of grants from Boston Scientific during the conduct of this study. LP reports personal fees and others from AstraZeneca, grants and other fees from GlaxoSmithKline, grants and personal fees from Esteve, personal fees and other fees from Boehringer, other fees from Teva, personal fees and other fees from Novartis, other fees from Chiesi, grants from Menarini, personal fees from MSD and Boston Scientific outside the submitted work. MN reports other fees from Boston Scientific. MB reports personal fees from Roche and Boehringer-Ingelheim outside the submitted work. DF reports other fees from Boston Scientific during the conduct of the study. PIB reports grants, non-financial support, and other fees from Boston Scientific during the conduct of the study. KD reports grants from Boston Scientific outside the submitted work. GMG is a full-time employee of Boston Scientific, the sponsor of this study. RN reports grants and personal fees from Boston Scientific outside the submitted work.

Patient consent for publication Not applicable.

Ethics approval This study involves human participants and was approved by The study was approved by the Ethics committee at each participating site. These committees were as follows: Comité Ético de Investigación Clínica Hospital General Universitario Gregorio Maranon for Hospital General Universitario Gregorio Maranon (number 347/13), Comité Ético de Investigación Clínica de la Fundacio de Gestio Sanitaria del Hospital de la Santa Creu I Sant Pau de Barcelona for Hospital de la Santa Creu i Sant Pau (\#13/173), Ethics Committee at General University Hospital, Prague for Klinika Tuberkulozy a Respiracnich Onemocneni (number 1882/13 S-IV/ ZP), Ethics Committee of the Medical Faculty HD for Thoraxklinik, University of Heidelberg (number S-613/2013), NHS Greater Glasgow and Clyde Health Board for Gartnavel General Hospital (number GC14RM003; 14/NW/0068), University Hospital of South Manchester NHS Foundation Trust for Wythenshawe Hospital University of Manchester (number 2014AS005; 14/NW/0068), Provincial Ethics Committee of the Province of Brescia for Azienda Ospedaliera Spedali Civili di Brescia (number NP 1513), Comitato Etico Provinciale di Reggio Emilia for Arcispedale Santa Maria Nuova (number 2015/0027339), HREC Faculty of Heath Sciences Universiy of Cape Town for University of Cape Town (number 723/2014), Fundación Jiménez Diaz Comité Ético de Investigación Clínica for Hospital Universitario Fundacion Jimenez Diaz (number EOH 2014/35), Comitè d'Ėtica de la Investigació del Hospital U. Germans Trias i Pujol for Hospital Germans Trias I Puyol (number PI-14-049), Independent Ethics Committee of Marche Region (CER) for Azienda Ospedaliero Universitaria Ospedali Riuniti (number 20150380 OR), Peninsula Health HREC for Peninsula Health (number LRR/15/PH/12), Royal Brisbane and Women's Hospital HREC for Royal Brisbane and Women's Hospital (number HREC/15/QRBW/448), Regensburg University Ethics Committee for University Hospital Regensburg (number 15-103-0256), Ethics Committee Faculty Of Medicine Of DuisburgEssen University for Ruhrlandklinik, Westdeutsches Lungenzentrum (number 16-6850-B0), Ethics Committee - Medical Faculty, Bonn for Universitätsklinikum Bonn (number 061/16), and AMC Medical Ethics Review Committee for Academic Medical Center (number W16_186 \# 16.243). Participants gave informed consent to participate in the study before taking part.

Provenance and peer review Not commissioned; externally peer reviewed. 
Data availability statement Data are available upon reasonable request. The data and study protocol for this clinical trial may be made available to other researchers in accordance with the Boston Scientific Data Sharing Policy (https://www. bostonscientific.com/en-US/data-sharing-requests.html). For questions related to Boston Scientific Data Sharing Requests contact ClinicalSolutions@bsci.com.

Supplemental material This content has been supplied by the author(s). It has not been vetted by BMJ Publishing Group Limited (BMJ) and may not have been peer-reviewed. Any opinions or recommendations discussed are solely those of the author(s) and are not endorsed by BMJ. BMJ disclaims all liability and responsibility arising from any reliance placed on the content. Where the content includes any translated material, BMJ does not warrant the accuracy and reliability of the translations (including but not limited to local regulations, clinical guidelines, terminology, drug names and drug dosages), and is not responsible for any error and/or omissions arising from translation and adaptation or otherwise.

Open access This is an open access article distributed in accordance with the Creative Commons Attribution Non Commercial (CC BY-NC 4.0) license, which permits others to distribute, remix, adapt, build upon this work non-commercially, and license their derivative works on different terms, provided the original work is properly cited, appropriate credit is given, any changes made indicated, and the use is non-commercial. See: http://creativecommons.org/licenses/by-nc/4.0/.

ORCID iD

Alfons Torrego http://orcid.org/0000-0001-6624-2465

\section{REFERENCES}

1 Kerkhof M, Tran TN, Soriano JB, et al. Healthcare resource use and costs of severe, uncontrolled eosinophilic asthma in the UK general population. Thorax 2018;73:116-24.

2 Nurmagambetov T, Kuwahara R, Garbe P. The economic burden of asthma in the United States, 2008-2013. Ann Am Thorac Soc 2018;15:348-56.

3 Jacob C, Bechtel B, Engel S, et al. Healthcare costs and resource utilization of asthma in Germany: a claims data analysis. Eur $J$ Health Econ 2016;17:195-201.

4 Chakir J, Haj-Salem I, Gras D, et al. Effects of bronchial thermoplasty on airway smooth muscle and collagen deposition in asthma. Ann Am Thorac Soc 2015;12:1612-8.

5 Pretolani M, Bergqvist A, Thabut G, et al. Effectiveness of bronchial thermoplasty in patients with severe refractory asthma: clinical and histopathologic correlations. J Allergy Clin Immunol 2017;139:1176-85.

6 Pretolani M, Dombret M-C, Thabut G, et al. Reduction of airway smooth muscle mass by bronchial thermoplasty in patients with severe asthma. Am J Respir Crit Care Med 2014;190:1452-4.

7 Salem IH, Boulet L-P, Biardel S, et al. Long-Term effects of bronchial thermoplasty on airway smooth muscle and reticular basement membrane thickness in severe asthma. Ann Am Thorac Soc 2016;13:1426-8.

8 Denner DR, Doeing DC, Hogarth DK, et al. Microbial and cytokine changes after bronchial thermoplasty in patients with severe asthma. American Journal of Respiratory and Critical Care Medicine $2015 ; 191$

9 Denner DR, Doeing DC, Hogarth DK, et al. Airway inflammation after bronchial thermoplasty for severe asthma. Ann Am Thorac Soc 2015;12:1302-9.

10 d'Hooghe JNS, Goorsenberg AWM, Ten Hacken NHT, et al. Airway smooth muscle reduction after bronchial thermoplasty in severe asthma correlates with FEV . Clin Exp Allergy 2019;49:541-4.

11 Dombret M-C, Alagha K, Boulet LP, et al. Bronchial thermoplasty: a new therapeutic option for the treatment of severe, uncontrolled asthma in adults. Eur Respir Rev 2014;23:510-8.
12 Salem H I, Biardel S, Chakir J, et al. Effects of bronchial thermoplasty (Bt) on airways in severe persistent asthma. American Journal of Respiratory and Critical Care Medicine 2014;189.

13 Castro M, Cox G. Asthma outcomes from bronchial thermoplasty in the AIR2 trial. Am J Respir Crit Care Med 2011;184:743-4.

14 Castro M, Rubin A, Laviolette M, et al. Persistence of effectiveness of bronchial thermoplasty in patients with severe asthma. Ann Allergy Asthma Immunol 2011;107:65-70.

15 Castro M, Musani Al, Mayse ML, et al. Bronchial thermoplasty: a novel technique in the treatment of severe asthma. Ther Adv Respir Dis 2010;4:101-16.

16 Wechsler ME, Laviolette M, Rubin AS, et al. Bronchial thermoplasty: long-term safety and effectiveness in patients with severe persistent asthma. J Allergy Clin Immunol 2013;132:1295-302.

17 Castro M, Rubin AS, Laviolette M, et al. Two-Year persistence of effect of bronchial thermoplasty $(\mathrm{Bt})$ in patients with severe asthma: AIR2 trial. Chest2010;138:768A.

18 Wechsler ME, Shah PL, Niven R, et al. Benefits of bronchial thermoplasty persist out to 5 years in patients with severe asthma. American Journal of Respiratory and Critical Care Medicine 2013;187.

19 Pavord I. 5-Year safety of bronchial thermoplasty demonstrated in patients with severe refractory asthma: research in severe asthma (RISA) trial. Am J Respir Crit Care Med 2011;183:A6382.

20 Castro M, Rubin AS, Laviolette M, et al. Effectiveness and safety of bronchial thermoplasty in the treatment of severe asthma: a multicenter, randomized, double-blind, sham-controlled clinical trial. Am J Respir Crit Care Med 2010;181:116-24.

21 Pavord ID. 5-Year safety of bronchial thermoplasty demonstrated in patients with severe refractory asthma: research in severe asthma (RISA) trial. American Journal of Respiratory and Critical Care Medicine 2011;183.

22 Chupp G, Laviolette M, Cohn L, et al. Long-Term outcomes of bronchial thermoplasty in subjects with severe asthma: a comparison of 3-year follow-up results from two prospective multicentre studies. Eur Respir J 2017;50:1700017.

23 Langton D, Sha J, Ing A, et al. Bronchial thermoplasty in severe asthma in Australia. Intern Med J 2017;47:536-41.

24 National Institutes of Health. Nih publication No. 97-4051, NAEPP expert panel report 3: guidelines for the diagnosis and management of asthma, 2007.

25 Chaudhuri R, Rubin A, Sumino K, et al. Safety and effectiveness of bronchial thermoplasty after 10 years in patients with persistent asthma (BT10+): a follow-up of three randomised controlled trials. Lancet Respir Med 2021;9:457-66.

26 Chung KF, Wenzel SE, Brozek JL, et al. International ERS/ATS guidelines on definition, evaluation and treatment of severe asthma. Eur Respir J 2014;43:343-73.

27 Pavord ID, Cox G, Thomson NC, et al. Safety and efficacy of bronchial thermoplasty in symptomatic, severe asthma. Am J Respir Crit Care Med 2007;176:1185-91.

28 Burn J, Sims AJ, Keltie K. S12 Efficacy of bronchial thermoplasty in clinical practice using the British Thoracic Society UK Difficult Asthma Registry and Hospital Episode Statistics: Abstract S12 Table 1. Thorax 2015;70:A11-11.

29 Burn J, Sims AJ, Keltie K, et al. Procedural and short-term safety of bronchial thermoplasty in clinical practice: evidence from a national registry and hospital episode statistics. Journal of Asthma 2017;54:872-9.

30 Niven RM, Simmonds MR, Cangelosi MJ, et al. Indirect comparison of bronchial thermoplasty versus omalizumab for uncontrolled severe asthma. J Asthma 2018;55:443-51.

31 Blaiss MS, Castro M, Chipps BE, et al. Guiding principles for use of newer biologics and bronchial thermoplasty for patients with severe asthma. Ann Allergy Asthma Immunol 2017;119:533-40.

32 Langton D, Sha J, Guo S, et al. Bronchial thermoplasty versus mepolizumab: comparison of outcomes in a severe asthma clinic. Respirology2020;25:1243-9. 